\title{
From paper to practice: an initial approach to implementation of the environmental monitoring plan for fish farming proposed by JACUMAR
}

\author{
Elena Martinez-Garcia ${ }^{1}$, Victoria Fernandez-Gonzalez ${ }^{1}$, Felipe Aguado-Giménez ${ }^{2}$, \\ José Luis Sánchez-Lizaso ${ }^{1}$, Pablo Sanchez-Jerez ${ }^{1}$ \\ ${ }^{1}$ Department of Marine Science and Applied Biology, University of Alicante, 03690 Alicante, Spain. \\ (EMG) (Corresponding author) E-mail: elena.martinez@ua.es. ORCID iD: https://orcid.org/0000-0003-4506-9442 \\ (VFG) E-mail: victoria.fernandez@ua.es. ORCID iD: https://orcid.org/0000-0002-5742-9831 \\ (JLSL) E-mail: jl.sanchez@ua.es. ORCID iD: https://orcid.org/0000-0002-3927-5699 \\ (PSJ) E-mail: psanchez@ua.es. ORCID iD: https://orcid.org/0000-0003-4047-238X \\ ${ }_{2}^{2}$ IMIDA, Estación Acuicultura Marina, Puerto de San Pedro del Pinatar, 30740 Murcia, Spain. \\ (FAG) E-mail: felipe.aguado@ carm.es. ORCID iD: https://orcid.org/0000-0001-8931-6180
}

\begin{abstract}
Summary: The Spanish National Advisory Board of Mariculture (JACUMAR) developed an initiative to unify methodologies between the regions of Spain, in which they proposed the implementation of site-specific "Environmental Monitoring Plans" (EMPs). In this study, we tested the feasibility of an EMP on a fish farm in the Mediterranean Sea. The methods and tools proposed in the EMP are highly useful for environmental monitoring of aquaculture. However, spatial heterogeneity figured prominently in a univariate analysis with environmental variables and a multivariate analysis of polychaete assemblages. This variability may be due to habitat patchiness, and may therefore be solved by an improved experimental design, e.g. by adding replications for increasing statistical power. Multivariate analysis of polychaete assemblages provided accurate information about the quality of the sediment. This information could also be improved using ecological data about key polychaete families in order to avoid misleading results. Thus, the JACUMAR EMP has proved useful in providing precise information about the ecological status of marine benthic habitats, meeting the requirements of current European Directives. However, we suggest that some modifications may be required in order to account for possible misleading thresholds for environmental quality standards, spatial heterogeneity and increasing power analyses.
\end{abstract}

Keywords: aquaculture; environmental management; spatial variations; abiotic parameters; polychaete assemblages; environmental monitoring plan.

Del papel a la práctica: una primera aproximación a la implementación del plan de seguimiento ambiental para acuicultura propuesto por JACUMAR

Resumen: La Junta Nacional Asesora de Cultivos Marinos (JACUMAR) desarrolló una iniciativa para unificar metodologías entre las regiones de España, en la que propusieron la implementación de "Planes de Seguimiento Ambiental" (EMP) específicos de cada caso. En este estudio se ha evaluado la viabilidad del EMP en una granja de peces del Mediterráneo. Los métodos y herramientas propuestos en el EMP son de gran utilidad para el seguimiento ambiental de la acuicultura. Sin embargo, la heterogeneidad espacial ha jugado un papel destacado en los análisis uni-variante con variables ambientales y multi-variante de las comunidades de poliquetos. Esta variabilidad puede ser debida a la heterogeneidad de los hábitats y, por tanto, debe resolverse mejorando el diseño experimental, p. ej. añadiendo réplicas en el muestreo para aumentar la potencia estadística. El análisis multi-variante de las comunidades de poliquetos ha proporcionado información precisa sobre la calidad del sedimento. Esta información también podría mejorarse utilizando datos ecológicos sobre las principales familias de poliquetos, con el fin de evitar resultados que pudieran inducir a errores. Por todo lo anterior, el EMP propuesto por JACUMAR ha demostrado ser útil para proporcionar información precisa sobre el estado ecológico de los hábitats bentónicos marinos, cumpliendo con los requisitos de las directivas europeas actuales. Sin embargo, los resultados de este artículo sugieren la conveniencia de realizar algunas modificaciones, con el objetivo de mejorar los umbrales para los estándares de calidad ambiental, la heterogeneidad espacial y la potencia de los análisis.

Palabras clave: acuicultura; gestión ambiental; variaciones espaciales; parámetros abióticos; comunidades de poliquetos; plan de seguimiento ambiental.

Citation/Como citar este artículo: Martinez-Garcia E., Fernandez-Gonzalez V., Aguado-Giménez F., Sánchez-Lizaso J.L., Sanchez-Jerez P. 2018. From paper to practice: an initial approach to implementation of the environmental monitoring plan for fish farming proposed by JACUMAR. Sci. Mar. 82(1): 27-34. https://doi.org/10.3989/scimar.04607.08A

Editor: E. Massuti. 
Received: January 9, 2017. Accepted: November 28, 2017. Published: December 18, 2017.

Copyright: (C) 2018 CSIC. This is an open-access article distributed under the terms of the Creative Commons Attribution 4.0 International (CC BY 4.0) License.

\section{INTRODUCTION}

The identification of indicators for the monitoring of aquaculture activities has been on the agenda of the FAO's General Fisheries Commission for the Mediterranean in recent decades (Massa and Bourdenet 2016). However, the need for effective monitoring protocols increased only when the European Water Framework Directive (WFD 2000/60/EC) and the Marine Strategy Framework Directive (MSFD 2008/56/EC) were proposed and Member States were required to achieve a "Good Environmental Status" in their marine waters. It is acknowledged that monitoring protocols for aquaculture, either as a mandatory or voluntary process, are highly inconsistent between countries and regions, ranging from very exhaustive studies to few or no requirements (Read and Fernandes 2003, Telfer et al. 2009). Thus, the broad variation in monitoring programmes and indicators used has resulted in a range of different approaches and conclusions about the spatial extent and severity of these effects (Kalantzi and Karakassis 2006). In Spain, specific guidelines were developed in order to maintain the ecosystem goods and services provided by the aquaculture activities (FOESA 2011). These guidelines focus on aspects such as the reduction of conversion factors, the compliance codes of good practices in aquaculture and the implementation of Environmental Monitoring Plans (EMPs). Because of the high legislative heterogeneity at regional level, the Spanish Ministry of Agriculture, Food and Environment, through the National Advisory Board of Mariculture (JACUMAR), developed an initiative to unify methodologies, proposing the implementation of site-specific EMPs (Aguado-Giménez et al. 2012).

This approach to EMPs focuses on the interactions between aquaculture and benthic ecosystems, in particular, increases in organic enrichment (from uneaten food and fish faeces) and the sensitiveness of benthic assemblages to detecting environmental impacts ( $\mathrm{Pa}-$ pageorgiou et al. 2010, Martinez-Garcia et al. 2013, Mangion et al. 2014). This incremental increase in organic matter $(\mathrm{OM})$ over the benthos may affect sediment biogeochemistry (Karakassis et al. 2005), causing oxygen depletion, augmentation of nutrient efflux and decreased benthic fauna diversity (Pearson and Rosenberg 1978, Hargrave et al. 2008, Martinez-Garcia et al. 2015). When oxygen concentration is reduced, aerobic metabolism is replaced by anaerobic metabolism, sulphate reduction and methanogenesis, producing sulphide and methane, which are harmful for macrobenthic fauna (Holmer et al. 2005, Hargrave et al. 2008). For this reason, a combination of biogeochemical variables and macrofauna are normally selected as bioindicators of aquaculture environmental impacts. The effect on macrofauna has been evaluated by multivariate analyses of the macrofauna assemblages and by using benthic biotic indices, which simplify the com- plex multivariate benthic assemblages up to a single value to describe the ecological status (Karakassis and Hatziyanni 2000, Hoey et al. 2010, Aguado-Giménez et al. 2015).

Among all macrobenthic faunal groups, the polychaete assemblages are commonly used for the analysis of disturbances produced by organic enrichment, due to their widespread distribution in the benthos, their trophic flexibility and their quick response to disturbances (Dean 2008). Differences in trophic strategies among species and families can lead to different responses to organic pollution. Some polychaetes are regarded as pollution tolerant, because they can survive in advanced stages of disturbance, while other species are regarded as pollution sensitive, because they are not able to persist under stress conditions (Pearson and Rosenberg 1978, Giangrande et al. 2005). Some authors (Tomassetti and Porrello 2005, Martinez-Garcia et al. 2013, Aguado-Giménez et al. 2015) have tested the use of polychaete assemblages to study disturbances originating from fish farm facilities and concluded that these assemblages give accurate information about the quality of the environment.

The aim of this study was to assess the feasibility of the EMP defined by JACUMAR (Aguado-Giménez et al. 2012) for monitoring the aquaculture effects on a Spanish fish farm. The proposed EMP included a specific design with hierarchical sampling along a gradient of distance from the fish cages, using physicochemical variables [sulphides, $\mathrm{OM}, \mathrm{pH}$, redox potential (Eh) and $\left.\delta^{15} \mathrm{~N}\right]$ and polychaete assemblages as bioindicators, followed by an adjustable monitoring programme. Thus, following the JACUMAR EMP guidelines, the environmental impact of a Mediterranean fish farm dedicated to seabream and seabass farming was evaluated with a particular focus on identifying possible improvements for future EMPs and examining the spatial consistency of the proposed variables that are necessary in order to detect environmental impacts.

\section{MATERIALS AND METHODS}

\section{Study area}

The study was carried out in 2009 in a sea bream and sea bass floating-cage farm at 25-30 m depth in Guardamar bay, southeast Spain (Fig. 1), with a mean annual production of around $1000 \mathrm{t}$ per year. The Segura River flows into Guardamar bay, so the study area was classified as 'a naturally-high organic concentration at a regional scale', as described in the JACUMAR protocol (Aguado-Giménez et al. 2012).

\section{Sampling strategy}

Samples were collected in late summer during the period of warmest water and maximum productivity. 


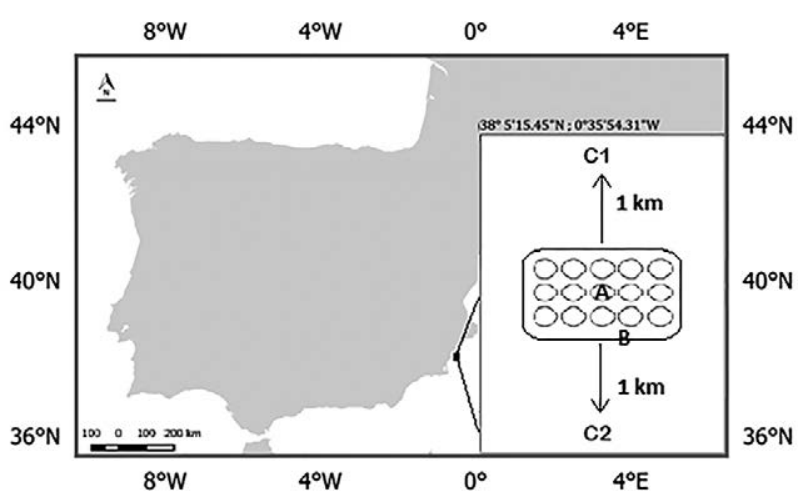

Fig. 1. - Location map of Guardamar bay and the fish farm, southeast Spain.

Four zones were sampled in the vicinity of the fish farm according to the EMP (Aguado-Giménez et al. 2012): zone A (just below the cages); zone B (50 m from the cages, at the edge of the farm facilities defined by the delimitation buoys); and zones $\mathrm{C} 1$ and $\mathrm{C} 2$ (reference areas placed $1 \mathrm{~km}$ away from the fish farm with a similar depth and the same type of sediment). Three stations in each zone were selected randomly, and each had three random replicates collected for sediment analyses and three separate replicates for polychaete assemblage structure. Samples were collected using a Van Veen grab $\left(0.04 \mathrm{~m}^{2}\right)$. Immediately after collection, the samples for the macrobenthos analyses were sieved with seawater through a 1-mm mesh net and the residues were preserved in $10 \%$ buffered formalin. At the laboratory, polychaetes were removed and preserved in $70 \%$ alcohol, and were later identified to family level. Total free sulphide content was measured with an ion-selective electrode (silver/sulphide combination electrode 9616 BNWP) following the method described by Wildish et al. (1999). Fractions of silt and clay (finest fraction $<0.0625 \mathrm{~mm}$ ) were determined by the wet-sieving method described by Buchanan (1984). OM was measured by loss on ignition $\left(400^{\circ} \mathrm{C}\right.$, 4 h; Buchanan 1984). $\mathrm{pH}$ and Eh were measured with CRISON electrodes. $\delta^{15} \mathrm{~N}$ isotopic composition was measured using an EA-IRMS (Thermo Finnigan) analyser in continuous flow configuration, combined with a stable ratio mass spectrometer Deltaplus. The $\delta^{15} \mathrm{~N}$ isotopic composition is expressed as:

$$
\delta^{15} \mathrm{~N}(\% \circ)=\left[\left(\mathrm{R}_{\text {sample }} / \mathrm{R}_{\text {standard }}\right)-1\right] 10^{3}
$$

where $R={ }^{15} \mathrm{~N} /{ }^{14} \mathrm{~N}$. The standard was atmospheric $\mathrm{N}_{2}$ while the analytical precision was $0.1 \%$ (Peterson and Fry 1987).

\section{Data analyses}

Values of environmental variables were classified by the environmental quality standards (EQS) proposed by JACUMAR (Table 1; AguadoGiménez et al. 2012). The data were analysed according to a two-factor model as suggested in the JACUMAR EMP (Aguado-Giménez et al. 2012), using the following model of sources of variability: $\mathrm{Xij}=\mu+\mathrm{Zi}+\mathrm{Sj}(\mathrm{Zi})+\mathrm{Residual}$, where $\mathrm{Z}$ refers to the zone (fixed and orthogonal with four levels: A, B, C1 and $\mathrm{C} 2$ ) and $\mathrm{S}$ refers to the stations (random and nested in Z, with three levels: Station 1, Station 2, Station 3). Analyses of variance (ANOVA) were used to analyse the environmental variables using the above model. Heterogeneity of variance was tested with Cochran's $\mathrm{C}$ test and data were transformed when necessary (Underwood 1997). Where variance remained heterogeneous, untransformed data were analysed and the $\alpha$-value was set at 0.01 , as ANOVA is robust for heterogeneity of variances, particularly for large, balanced experiments (Underwood 1997). Where significant differences were found, data were subsequently investigated using an SNK test (Student-NewmanKeuls) to determine which samples were involved in the differences. The software R (R Development Core Team 2011) was used with the GAD package (Sandrini-Neto and Camargo 2014) for the ANOVA analyses. To investigate the effects on the polychaete assemblages, the model was analysed using permutational multivariate analysis of variance (PERMANOVA). Pairwise tests and Monte Carlo tests were used to detect differences between levels of the factor $\mathrm{Z}$ (Anderson and Robinson 2003). Differences in polychaete assemblage structure were explored using nonparametric multidimensional scaling (MDS; Clarke 1993) and similarity percentages (SIMPER) between zones (Clarke 1993). To assist with the interpretation of analyses, the variability at each spatial scale was expressed as a component of variation (sum of all

Table 1. - Summary of the environmental quality standards (EQS) proposed by the JACUMAR EMP. Zone A, inside the perimeter of the lease-hold area physically below the facilities; zone B, area surrounding the administrative concession, no more than $50 \mathrm{~m}$ outside the limits.

\begin{tabular}{|c|c|c|}
\hline & \multicolumn{2}{|c|}{ Environmental Quality Standards (EQS) } \\
\hline & Zone A & Zone B \\
\hline Total free sulphide (TFS) & $\begin{array}{l}<3000 \mu \mathrm{M} \\
<3 \text { samples over } 5000 \mu \mathrm{M}\end{array}$ & $\begin{array}{l}<3000 \mu \mathrm{M} \\
<50 \% \text { higher than zones } \mathrm{C}\end{array}$ \\
\hline Finest fraction & $<50 \%$ higher than zones $\mathrm{C}$ & $<25 \%$ higher than zones $\mathrm{C}$ \\
\hline Organic matter $(\mathrm{OM})$ & $<50 \%$ higher than zones $\mathrm{C}$ & $=$ zones $\mathrm{C}$ \\
\hline $\mathrm{pH}$ & Between 7 and 9 & $\begin{array}{l}\text { Between } 7.5 \text { and } 8.5 \\
\text { Special case: }=\text { zones C }\end{array}$ \\
\hline Redox potential (Eh) & $\begin{array}{l}\text { Zone A } \\
\text { Special case: }-50 \text { and }-100 \mathrm{mV} \text { higher than zone } \mathrm{C}\end{array}$ & $\begin{array}{l}\text { Between }-50 \text { and }-100 \mathrm{mV} \text { higher than zone } \mathrm{C} \\
\text { Special case: }=\text { zones } \mathrm{C}\end{array}$ \\
\hline$\delta^{15} \mathrm{~N}$ & $<6 \%$ or $<4$ units higher than zones $\mathrm{C}$ & $=$ zones $\mathrm{C}$ \\
\hline Polychaete assemblage & $\begin{array}{l}<75 \% \text { less families than zones } \mathrm{C} \\
<75 \% \text { dissimilarity compared to zones } \mathrm{C}\end{array}$ & $\begin{array}{l}<50 \% \text { less families than zones } \mathrm{C} \\
<50 \% \text { dissimilarity compared to zones } \mathrm{C}\end{array}$ \\
\hline
\end{tabular}


Table 2. - Results of ANOVA, PERMANOVA and pairwise test with two factors. Df, degrees of freedom; MS, mean square; F, F-distribution; MC, Monte Carlo test. Levels of significance: $* \mathrm{p}<0.05$, $* * \mathrm{p}<0.01$ and $* * * \mathrm{p}<0.001$. -a indicates that there was no homogeneity of variance; the levels of significance were $* \mathrm{p}<0.01, * * \mathrm{p}<0.001$. CV, components of variation. A, fish farm; B, intermediate; C1, control 1; C2, control 2.

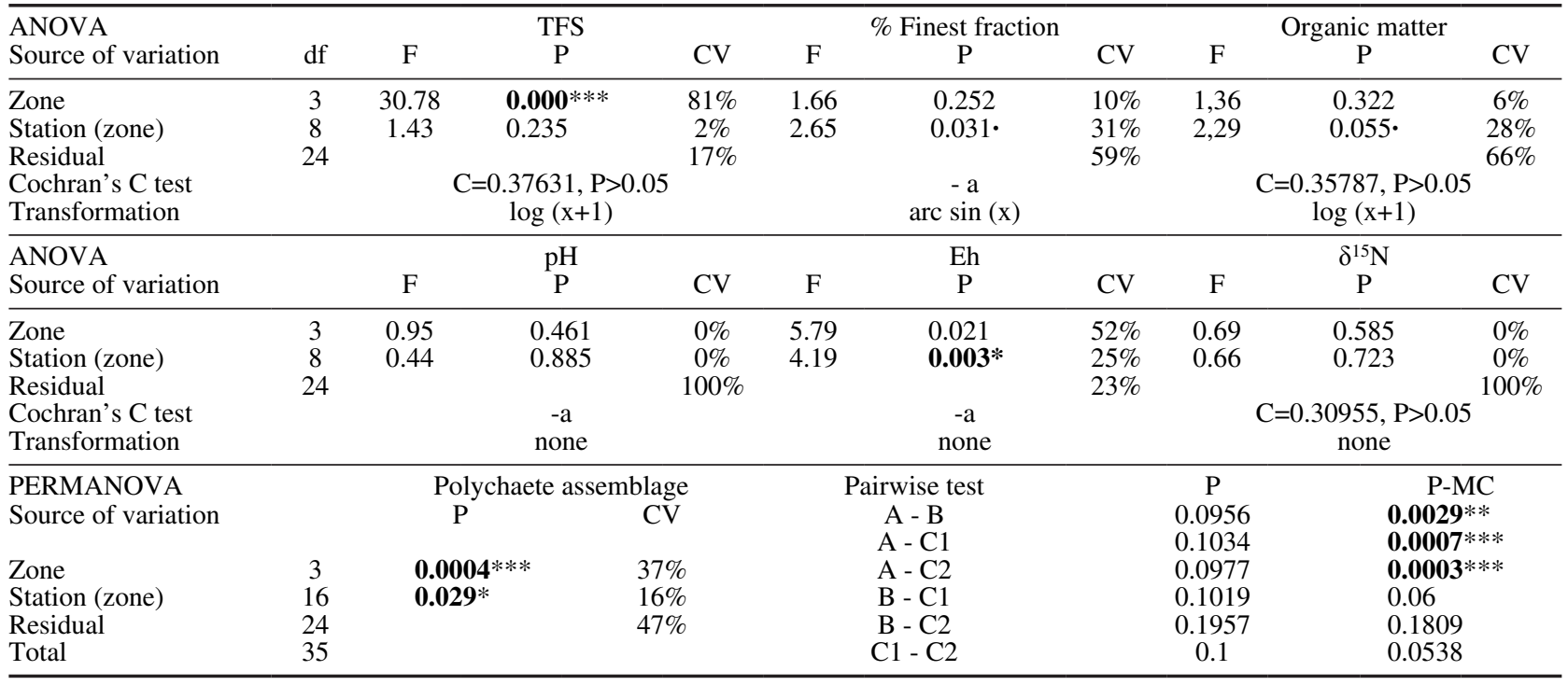

pseudo-variance components) (Anderson et al. 2005). Multivariate statistical analyses were performed using PRIMER-E software (PRIMER software, Clarke and Gorley 2006) with the PERMANOVA+ package (Anderson et al. 2008).

\section{RESULTS}

ANOVA analysis of the environmental variables showed that total free sulphide (TFS) was the most sensitive environmental variable to the fish farming activity, showing significant differences for zone factor (Table 2), with zone A having significantly higher values than the other zones (SNK: $\mathrm{A}>\mathrm{B}>\mathrm{C} 2>\mathrm{C} 1$, Fig. $2)$. The remaining indicators showed no significant differences between farm and control locations. There was high spatial variability across stations for all indicators except $\mathrm{pH}$, TFS and $\delta^{15} \mathrm{~N}$, for which Eh was the most spatially inconsistent (Table 2). The components of variation showed that TFS and Eh had the highest variation among zones, at the scale of hundreds of metres, while the proportion of the finest fraction, $\mathrm{pH}$,
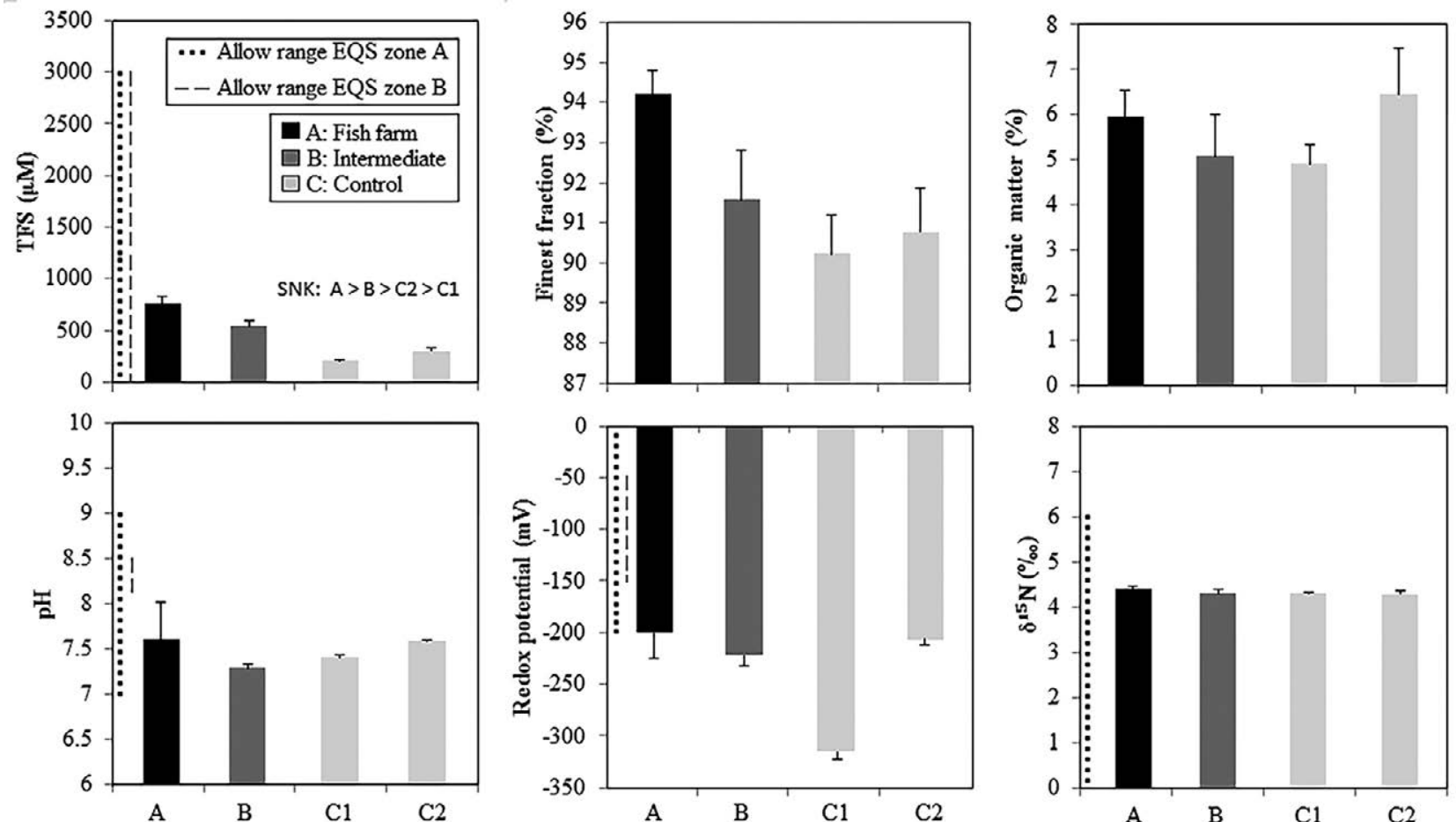

Fig. 2. - Mean values ( \pm standard error) of total free sulphides (TFS), finest fraction (\%), organic matter $(\%)$, pH, redox potential $(\mathrm{mV})$ and $\delta^{15} \mathrm{~N}$. 
$\mathrm{OM}$ and $\delta^{15} \mathrm{~N}$ reflected a higher proportion of variation among replicates at a scale of metres (Table 2).

Despite the significant differences observed in the ANOVA analysis, TFS concentration did not exceed the permitted limits established by the EQS proposed by JACUMAR (Table 1, Aguado-Giménez et al. 2012), with values between 493-1269 $\mu \mathrm{M}$ at zone A and 378$787 \mu \mathrm{M}$ at zone B (Fig. 2). In zone A, there was no sample above $5000 \mu \mathrm{M}$. However, in zone B, the TFS concentration was $267 \%$ and $179 \%$ higher than in $\mathrm{C} 1$ and $\mathrm{C} 2$, respectively. The percentage of the finest fraction did not exceed the EQS because values in zones $\mathrm{A}$ and $\mathrm{B}$ were not $50 \%$ and $25 \%$ higher than zones $\mathrm{C} 1$ and $\mathrm{C} 2$, respectively (Fig. 2). OM did not exceed the limit established by the EQS because values in zone A were not $50 \%$ higher than in zones $\mathrm{C} 1$ and $\mathrm{C} 2$. The $\mathrm{pH}$ values in zone $\mathrm{A}$ were inside the allowable range, but those in zone B were lower than the permitted limits (Fig. 2). This represented the special case considered in the EMP (Aguado-Giménez et al. 2012) for areas with a naturally high OM content (due to the outflow of the Segura River), and no significant differences in $\mathrm{pH}$ were found between zones $\mathrm{C} 1$ and $\mathrm{C} 2$ and zone $\mathrm{B}$ in $\mathrm{pH}$ (Table 2). Eh values in all zones fell outside the allowable range proposed by JACUMAR. Likewise, as it was an area with a naturally high OM content, the EMP proposed a statistical hypothesis test, which showed that zone A was no more electronegative than $\mathrm{C} 1$ and $\mathrm{C} 2$ (Fig. 2), and zone B did not differ significantly from zones $\mathrm{C} 1$ and $\mathrm{C} 2$ (Table 2 ). $\delta^{15} \mathrm{~N}$ values were very similar across zones and did not exceed the EQS in any samples (Fig. 2).

PERMANOVA analysis of polychaete families showed significant differences among zones in spite of the spatial variability among stations (Table 2). When a pairwise test was applied, only zone A was significantly different to zones B, C1 and C2. The composition of variance showed that the variability occurred at a scale of metres between replicates, and at a zone scale of hundreds of metres (Table 2).

The MDS analysis of the polychaete assemblage structure was in agreement with the PERMANOVA results, as zones C1, C2 and B were tightly clustered, and zone A appeared to be separated in the plot. Moreover,

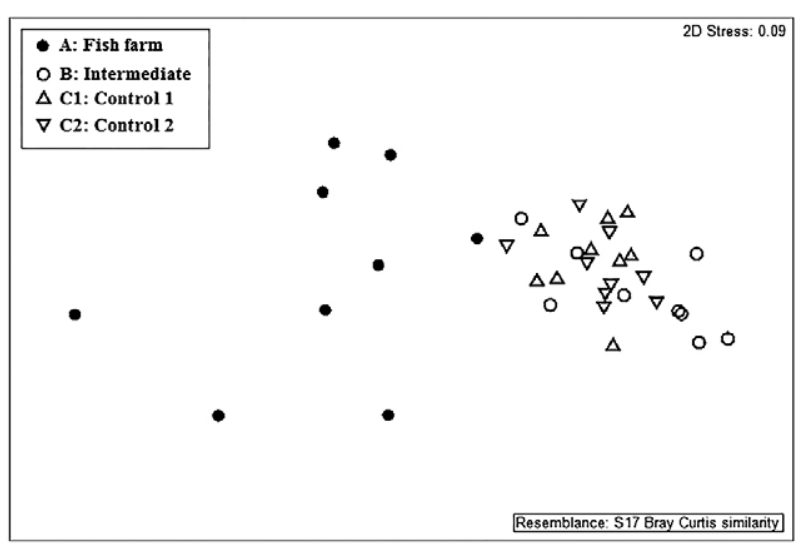

Fig. 3. - Non-metric multidimensional scaling ordination analysis on the Bray-Curtis similarity of non-transformed abundance data of polychaete families.
Table 3. - Summary of SIMPER dissimilarities of polychaete assemblages in the four zones, A, fish farm; B, intermediate; $\mathrm{C} 1$, control 1; C2, control 2. Aver. Dissim, average dissimilarity. \% $\mathrm{n}^{\circ}$ families, percentage of the polychaete families in $\mathrm{A}$ and $\mathrm{B}$ in comparison with $\mathrm{C} 1$ and $\mathrm{C} 2$. EQS, environmental quality standard proposed by JACUMAR EMP.

\begin{tabular}{lccc}
\hline \multicolumn{4}{c}{ Polychaete assemblage } \\
Zone & Aver. Dissim. \% & $\mathrm{n}^{\mathbf{0}}$ families & EQS \\
\hline A - C1 & $\mathbf{8 3 . 8 7}$ & $<\mathbf{6 4 . 6 3}$ & $<75$ \\
A - C2 & $\mathbf{8 3 . 8 2}$ & $<\mathbf{7 0 . 1 0}$ & $<75$ \\
B - C1 & $\mathbf{5 3 . 9 7}$ & $>17.07$ & $<50$ \\
B - C2 & 48.95 & $<1.03$ & $<50$ \\
A - B & 86.53 & & \\
C1 - C2 & 44.4 & & \\
\hline
\end{tabular}

zone A showed higher scatter between its samples (Fig. 3). The SIMPER test indicated that the dissimilarities between zone $\mathrm{A}$ and $\mathrm{C} 1$ and $\mathrm{C} 2$ were $83.87 \%$ and $83.82 \%$, respectively. Zone B was less dissimilar than the control zones, with values of $48.95 \%(\mathrm{C} 2)$ and $53.973 \%(\mathrm{C} 1)$, in the latter case slightly exceeding the EQS (Table 3). The number of families in zone A was $64.63 \%$ and $70.10 \%$ lower than zones $\mathrm{C} 1$ and $\mathrm{C} 2$, respectively, exceeding the EQS; conversely, the number of families in zone B was $17.07 \%$ higher than zone $\mathrm{C} 1$ and $1.03 \%$ lower than zone C2 (Table 3 ).

\section{DISCUSSION}

The application of EMPs proposed by JACUMAR (Aguado-Giménez et al. 2012) led to the detection of an environmental impact due to fish farming, mainly in TFS and polychaete assemblages. Therefore, we conclude that there was a localized environmental impact just underneath the cages, inside the Allowable Zone of Effect. Among all physicochemical variables, only TFS showed significant differences between the impacted and control zones, and only TFS in zone B exceeded the EQS proposed by the JACUMAR approach. Polychaete assemblages at family level were the best indicator of fish farming impacts, as they were sensitive enough to detect an environmental impact in spite of the above-mentioned minor physicochemical effects. However, high spatial variability observed at different scales for several indicators could affect statistical power and increase the probability of a type II statistical error (Underwood 1997). Natural variability between control zones could also negatively affect an environmental impact assessment. From these results we can conclude that although this EMP proposal includes a complementary set of methods and tools that seem to be appropriate for fish farming environmental monitoring, some improvements could be made in order to deal with spatial variability, increased sampling robustness and reducing type II errors, and thus reduce uncertainty in interpreting the results.

The spatial variability for geochemical and biological variables is a normal consequence of benthic assemblage patchiness and irregular disturbance of the seabed by fish farming. This variability can affect the sediment mostly at a scale of metres (Quintino et al. 2006, Fernandez-Gonzalez et al. 2013), as found in this study for some geochemical parameters $(\mathrm{pH}$, finest fraction $\%, \mathrm{OM}$ and $\left.\delta^{15} \mathrm{~N}\right)$, and for polychaete 
assemblages. This significant variability at replicate level confirms the well-known importance of selecting a representative sample size in terms of the volume of sampled sediment and the number of replicates (Andrew and Mapstone 1987). Other variables were affected at a scale of hundreds of metres (TFS, Eh and polychaete assemblage), reflecting the interaction of the fish farm cages with the benthic habitat. In some uncertain situations, it may be appropriate to use a higher level of significance (e.g. $\alpha=0.1$ ) in order to avoid overlooking slight environmental impacts, thus using a precautionary approach to reduce type II errors, e.g. when the EQS of polychaete assemblages are exceeded but not for physicochemical variables. Replication in higher spatial cases (e.g. nested stations within zones), as performed in this EMP (Underwood 1997, Terlizzi et al. 2005), will increase statistical power and avoid pseudoreplication (Hurlbert 1984), and would be necessary for detecting organic enrichment from fish farm facilities in a naturally patchy environment.

Dissimilarity tests for polychaete assemblages concluded that values in zones A and B exceeded the EQS proposed by JACUMAR. In this aspect of sensitivity, polychaete assemblages at family level appeared to be a very good tool for identifying changes in the benthic ecosystem, allowing slight differences between zones to be detected even with high spatial heterogeneity. Polychaete assemblages showed higher spatial variability below the fish farm than in other zones. This increased variability has been considered to be a general feature of assemblages in stressed environments and could be due to several scenarios: changes in total cover or total number of taxa, changes in the variance-to-mean ratio for particular species, or changes in taxonomic composition (Warwick and Clarke 1993, Chapman et al. 1995, Terlizzi et al. 2005). However, in this case, the dissimilarity results shown in SIMPER, in which zone $\mathrm{B}$ was over the limits, are quite misleading regarding the decrease in the number of families, PERMANOVA showed no significant differences between zone B and zones $\mathrm{C} 1$ and $\mathrm{C} 2$, and MDS clustered all these zones together. In borderline cases such as this, managers may find it difficult to decide whether to apply administrative measures against the farmer. If the SIMPER result was outside the EQS but PERMANOVA and MDS were inside the EQS, should the manager apply any measure? A precautionary approach could be implemented and mitigation measures could be agreed in consensus with the farmer, following a good practice code (FEAP 2006). However, observing the natural variability and the dissimilitude result between $\mathrm{C} 1$ and $\mathrm{C} 2$, a revision of the EQS would be appropriate. We would propose that the limit in zone B $(50 \%$ of families and $50 \%$ of dissimilitude compared with zone C) may be increased to $65 \%$ without jeopardizing the achievement of EQS. In the farm studied with this new EQS, the results would have more concordance and only zone A would be outside the EQS.

Analysis of polychaete assemblages could be enhanced with ecological information from univariate analysis of polychaete families. Polychaetes have been well documented as bioindicators, specifically species such as Capitella capitata or some Spionidae species (Pearson and Rosenberg 1978, Giangrande et al. 2005, Tomassetti et al. 2005). Moreover, studying the whole assemblage at family level and following general patterns of family abundance, as described by MartinezGarcia et al. (2013), provides accurate information on the quality of the benthic environment. In this manner, information provided by polychaete assemblages will not be restricted to the number of families and the dissimilarity value, which is a simplified number that summarizes an overall ecological process, as happens with the biotic indices (Aguado-Giménez et al. 2015). Therefore, univariate analyses of selected polychaete families should also be carried out in order to provide more information on the ecological processes occurring due to fish farming. Considering that classification of polychaetes at family level is required to perform multivariate analyses, this approach would not require additional taxonomic effort.

Sulphide measurements, such as TFS, are able to show variations in biogeochemical processes of the sediment due to organic enrichment (Wildish et al. 1999), even when the input is not high enough to be detected by OM measurements (Martinez-Garcia et al. 2015). Thus, some authors have proposed TFS as an indicator to be included in EMPs (Katavić et al. 2005, AguadoGiménez et al. 2015). In these EMPs, sulphide concentration from zone A and B must be compared with that in control areas by contrasting hypotheses. By this method, in this study, differences produced by the fish farming were detected. Zones A and B were within the permitted limit set by JACUMAR EQS. Again, this could cause a controversial situation for the managers, as zone A clearly suffered statistically significant impacts, and this result was in line with polychaete assemblage results. By contrast, zone B was slightly altered, beyond the limit of $50 \%$ higher than controls, but, if these data were related to the polychaete assemblage, the MDS and PERMANOVA showed no important biotic impact caused by the sulphide value in zone B. The EQS limits set by JACUMAR were probably overly high, so other fish farm facilities may be wrongly considered to be within the EQS. We would propose that, coupled with the hypothesis test, an increased percentage threshold with respect to zone $\mathrm{C}$ may be added. For areas with naturally-high organic enrichment such as Guardamar bay, the limit for zone A could be significantly different, with double the concentration in zone C. Sulphide concentration limit in zone B could also be revised, taking into account that there was a difference of $50 \%$ between $\mathrm{C} 1$ and $\mathrm{C} 2$. Another suggestion for the limit may be to double the concentration of controls. If these new limits were implemented in the studied fish farm, zone A would clearly exceed the EQS, and zone B would be close to the upper limit but within the EQS compared with $\mathrm{C} 2$ and outside the EQS compared with $\mathrm{C} 1$.

After many years using Eh to add information on the degree of organic enrichment, some authors do not advocate its use in finfish monitoring. This is due to the problems associated with potential "poisoning" of the probes and the high variability in the Eh measures, and the difficulty of obtaining a stable reading that was also 
encountered in the present study (Wildish et al. 2005, MER 2008). $\delta^{15} \mathrm{~N}$ has been used as a good tracer of fish farm waste (Holmer and Frederiksen 2007, Ruiz et al. 2010), but in this study, $\delta^{15} \mathrm{~N}$ results showed no sign of fish farm effect even below the cages. Considering that it is an expensive variable to measure, we would not propose this variable in EMPs.

A more exhaustive EMP with increased periodicity may be required if surveys reveal significant negative impacts. An adjustable EMP is proposed by JACUMAR for Spain, as has been done by Norway and Croatia (Ervik et al. 1997, Katavić et al. 2005). However, in some situations, as shown in the present study, contradictory results could affect the implementation of an adjustable EMP. According to the results of the present study, following an adjustable EMP (Katavić et al. 2005), it would be necessary to adapt the EMP of the studied fish farm by increasing the sampling periodicity of polychaete assemblages and TFS to a survey every six months, until the values were again within the EQS. If the environmental impact persisted over time, mitigation measures would also be required, such as reducing productivity or relocating facilities to deeper waters.

Consensus about monitoring protocols is needed to ensure that data meet defined standards of quality with a known level of confidence, in order to be credible to external review and allow comparisons between places, regions and agencies. The proposed EMP of JACUMAR seems to be a very innovative approach and a reliable tool for monitoring fish farming along a scale of thousands of kilometres along the entire Spanish coast, and this kind of proposal could be considered for implementation in other European and Mediterranean countries with fish farming under similar environmental conditions. Moreover, this EMP is pioneering in adding a hypothesis test as an EQS for fish farm monitoring, and in proposing comparisons with control locations as natural background values. However, in some cases higher statistical power with regard to univariate and multivariate analysis is needed in order to accurately determine the effects of fish farming.

Therefore, before full implementation of JACUMAR EMP in Spain, it will be necessary to evaluate the need to increase spatial replication at several scales, contrasting the information obtained from various pilot cases. A revision of EQS for environmental variables will be recommended for TFS and polychaete assemblage with the addition of ecological information about their families. The use of Eh and $\delta^{15} \mathrm{~N}$ would be unwise. Moreover, iterative EMP will be important in order to trace the progression of fish farm activity in relation to benthic environmental quality (Aguado-Giménez et al. 2012), and long temp data series from fish farming EMPs carried out with the same methodology will be very informative, giving more accurate information about their environmental status, as required by the European directives (Hoey et al. 2010). Therefore, we encourage future steps for harmonization of EMP at national, European or even Mediterranean scale, such as this EMP proposed by JACUMAR for Spanish coastlines.

\section{ACKNOWLEDGEMENTS}

We are grateful to the CULMAR fish farm for giving us access and providing assistance during the study. We thank "Spanish National Plans of Aquaculture" (JACUMAR) in particular for the project "Selección de indicadores, determinación de valores de referencia, diseño de programas y protocolos de métodos y medidas para estudios ambientales en acuicultura marina". We also thank Nick Marchant for his assistance with the English version.

\section{REFERENCES}

Aguado-Giménez F., Carballeira Ocaña A., Collado Sánchez C. et al. 2012. Propuesta Metodológica para la realización de los planes de vigilancia ambiental de los cultivos marinos en jaulas flotantes. Junta Nacional Asesora de Cultivos Marinos (JACUMAR). Ministerio de Agricultura, Alimentación y Medio Ambiente, $164 \mathrm{pp}$.

Aguado-Giménez F., Gairín J.I., Martinez-Garcia E., et al. 2015. Application of "taxocene surrogation" and "taxonomic sufficiency" concepts to fish farming environmental monitoring. Comparison of BOPA index versus polychaete assemblage structure. Mar. Environ. Res. 103: 27-35. https://doi.org/10.1016/j.marenvres.2014.10.006

Anderson M.J., Robinson J. 2003. Generalized discriminant analysis based on distances. Aust. NZ. J. Stat. 43: 301-318. https://doi.org/10.1111/1467-842X.00285

Anderson M.J., Connell S.D., Gillanders B.M., et al. 2005. Relationships between taxonomic resolution and spatial scales of multivariate variation. J. Anim. Ecol. 74: 636-646. https://doi.org/10.1111/j.1365-2656.2005.00959.x

Anderson M.J., Gorley R.N., Clarke K.R. 2008. PERMANOVA+ for PRIMER: guide to software and statistical methods.PRIMER-E, Plymouth, 214 pp.

Andrew N.L., Mapstone B.D. 1987. Sampling and the description of spatial pattern in marine ecology. Oceanogr. Mar. Biol. 25: $39-90$.

Buchanan J.B. 1984. Sediment analysis. In: Holme N.A., McIntyre A.D. (eds) Methods for the study of marine benthos. Blackwell Scientific Publications, Oxford, pp. 41-64.

Clarke K.R. 1993. Non-parametric multivariate analysis of changes in community structure. Aust. J. Ecol. 18: 117-143. https://doi.org/10.1111/j.1442-9993.1993.tb00438.x

Clarke K.R., Gorley R.N. 2006. PRIMER v6: user manual/tutorial. PRIMER-E, Plymouth, 190 pp.

Chapman M.G., Underwood A.J., Skilleter G.A. 1995. Variability at different spatial scales between a subtidal assemblage exposed to the discharge of sewage and two control assemblages. J. Exp. Mar. Biol. Ecol. 189: 103-122. https://doi.org/10.1016/0022-0981(95)00017-L

Dean K.H. 2008. The use of polychaetes (Annelida) as indicator species of marine pollution: a review. Rev. Biol. Trop. 56: 11-38.

Ervik A., Hansen P.K., Aure J., et al. 1997. Regulating the local environmental impact of intensive marine fish farming I. The concept of the MOM system (Modelling-Ongrowing fish farmsMonitoring). Aquaculture 158: 85-94. https://doi.org/10.1016/S0044-8486(97)00186-5

FEAP (Federation of European Aquaculture Producers). 2006. Code of Conduct. Liège, Belgium, Federation of European Aquaculture Producers. Www.feap.info

Fernandez-Gonzalez V., Aguado-Giménez F., Gairin J.I., et al. 2013. Exploring patterns of variation in amphipod assemblages at multiple spatial scales: natural variability versus coastal aquaculture effect. Aquacult. Environ. Interact. 3: 93-105. https://doi.org/10.3354/aei00054

FOESA. 2011. Indicadores de sostenibilidad para viveros flotantes en la acuicultura marina Mediterránea. FOESA, Madrid, España. $116 \mathrm{pp}$.

Giangrande A., Licciano M., Musco L. 2005. Polychaetes as environmental indicators revisited. Mar. Pollut. Bull. 50: 1153-1162. https://doi.org/10.1016/j.marpolbul.2005.08.003

Hargrave B.T., Holmer M., Newcombe C.P. 2008. Towards a classification of organic enrichment in marine sediments based on 
biogeochemical indicators. Mar. Pollut. Bull. 56: 810-824. https://doi.org/10.1016/j.marpolbul.2008.02.006

Hoey G.V., Borja A., Birchenough S., et al. 2010. The use of benthic indicators in Europe: From the Water Framework Directive to the Marine Strategy Framework Directive. Mar. Pollut. Bull. 60: 2187-2196.

https://doi.org/10.1016/j.marpolbul.2010.09.015

Holmer M., Frederiksen M.S. 2007. Stimulation of sulfate reduction rates in Mediterranean fish farm sediments inhabited by the seagrass Posidonia oceanica. Biogeochemistry 85: 169-184. https://doi.org/10.1007/s10533-007-9127-x

Holmer M., Wildish D., Hargrave B. 2005. Organic enrichment from marine finfish aquaculture and effects on sediment processes. In: Hargrave B.T. (ed.), The Handbook of Environmental Chemistry, Water Pollution. Environmental Effects of Marine Finfish Aquaculture, vol. 5. Springer Verlag, pp. 181-206. https://doi.org/10.1007/b136010

Hurlbert S.J. 1984. Pseudoreplication and the design of ecological field experiments. Ecol. Monogr. 54: 187-211. https://doi.org/10.2307/1942661

Kalantzi I., Karakassis I. 2006. Benthic impacts of fish farming: Meta-analysis of community and geochemical data. Mar. Pollut. Bull. 52: 484-493. https://doi.org/10.1016/j.marpolbul.2005.09.034

Karakassis I., Hatziyanni E. 2000. Benthic disturbance due to fish farming analyzed under different levels of taxonomic resolution. Mar. Ecol. Prog. Ser. 203: 247-253. https://doi.org/10.3354/meps203247

Karakassis I., Pitta P., Krom M.D. 2005. Contribution of fish farming to the nutrient loading of the Mediterranean. Sci. Mar. 69: 313-321. https://doi.org/10.3989/scimar.2005.69n2313

Katavić I., Herstad T.J., Kryvi H., et al. 2005. Guidelines to marine aquaculture planning, integration and monitoring in Croatia. Project "Coastal zone management plan for Croatia", Zagreb, 78 pp.

Mangion M., Borg J.A., Thompson R., et al. 2014. Influence of tuna penning activities on soft bottom macrobenthic. Mar. Pollut. Bull. 79: 164-174. https://doi.org/10.1016/j.marpolbul.2013.12.021

Martinez-Garcia E., Sanchez-Jerez P., Aguado-Giménez F., et al. 2013. A meta-analysis approach to the effects of fish farming on soft bottom polychaeta assemblages in temperate regions. Mar. Pollut. Bull. 69: 165-171. https://doi.org/10.1016/j.marpolbul.2013.01.032

Martinez-Garcia E., Sundstein-Carlsson M., Sanchez-Jerez P., et al 2015. Effect of sediment grain size and bioturbation on decomposition of organic matter from aquaculture. Biogeochemistry 125: $133-148$. https://doi.org/10.1007/s10533-015-0119-y

Massa F., Bourdenet D. 2016. Sustainable Aquaculture Development in the Mediterranean and the Black Sea. FAO Aquaculture Newsletter 54 March.

MER 2008. Evaluation of the variability, applicability, and suitability of the redox potential and total sulfide measurement methodologies (Wildish et al. 1999) for determining benthic organic enrichment state and their use as regulatory compliance standards in Maine. Report prepared for the Maine Aquaculture Innovation Center (MAIC), 28 February 2008, $51 \mathrm{pp}$.

MSFD (Marine Strategy Framework Directive). 2008. Directive 2008/56/EC of the European Parliament and of the Council of 17 June 2008 establishing a framework for community action in the field of marine environmental policy.
Papageorgiou N., Kalantzi I., Karakassis I. 2010. Effects of fish farming on the biological and geochemical properties of muddy and sandy sediments in the Mediterranean Sea. Mar. Environ. Res. 69: 326-336. https://doi.org/10.1016/j.marenvres.2009.12.007

Pearson T.H., Rosenberg R. 1978. Macrobenthic succession in relation to organic enrichment and pollution of the marine environment. Oceanogr. Mar. Biol. Ann. Rev. 16: 229-311.

Peterson B.J., Fry B. 1987. Stable isotopes in ecosystem studies. Ann. Rev. Ecol. Syst. 18: 293-320. https://doi.org/10.1146/annurev.es.18.110187.001453

Quintino V., Elliott M., Rodrigues A.M. 2006. The derivation, performance and role of univariate and multivariate indicators of benthic change: Case studies at differing spatial scales. J. Exp. Mar. Biol. Ecol. 330: 368-382. https://doi.org/10.1016/j.jembe.2005.12.040

R Development Core Team. 2011. R: A language and environment for statistical computing. R Foundation for Statistical Computing, Vienna, Austria. www.R-project.org

Read P., Fernandes T. 2003. Management of environmental impacts of marine aquaculture in Europe. Aquaculture 226: 139-163. https://doi.org/10.1016/S0044-8486(03)00474-5

Ruiz J.M., Marco-Méndez C., Sánchez-Lizaso J.L. 2010. Remote influence of off-shore fish farm waste on Mediterranean seagrass (Posidonia oceanica) meadows. Mar. Environ. Res. 69: 118-126. https://doi.org/10.1016/j.marenvres.2009.09.002

Sandrini-Neto L., Camargo M.G. 2014. GAD: An R package for ANOVA designs from general principles, available on CRAN.

Telfer T.C., Atkin H., Corner R.A. 2009. Review of environmental impact assessment and monitoring of aquaculture in Europe and North America. In: FAO. Environmental impact assessment and monitoring in aquaculture. FAO Fisheries and Aquaculture Technical Paper, 527. Rome, FAO, pp. 285-394.

Terlizzi A., Benedetti-Cecchi L., Bevilacqua S., et al. 2005. Multivariate and univariate asymmetrical analyses in environmental impact assessment: a case study of Mediterranean subtidal sessile assemblages. Mar. Ecol. Prog. Ser. 289: 27-42. https://doi.org/10.3354/meps289027

Tomassetti P., Porrello S. 2005. Polychaetes as indicators of marine fish farm organic enrichment. Aquacult. Int. 13: 109-128. https://doi.org/10.1007/s10499-004-9026-2

Underwood A.J. 1997. Experiments in Ecology: their logical design and interpretation using analysis of variance. Cambridge University Press, Cambridge, $504 \mathrm{pp}$.

Warwick R.M., Clarke K.R. 1993. Increased variability as a symptom of stress in marine communities. J. Exp. Mar. Biol. Ecol. 172: $215-226$ https://doi.org/10.1016/0022-0981(93)90098-9

WFD. 2000. Directive 2000/60/EC of the European Parliament and the Council Establishing a Framework for the Community Action in the Field of Water Policy.

Wildish D.J., Akagi H.M., Hamilton N., et al. 1999. A recommended method for monitoring sediments to detect organic enrichment from mariculture in the Bay of Fundy. Can. Tech. Rep. Fish. Aquat. Sci. 2286: 1-34.

Wildish D.J., Pohle G.W., Hargrave B.T., et al. 2005. Benthic monitoring methods for habitat management of finfish mariculture in Canada. Canadian Science Advisory Secretariat, Research Document 2005/039, 39 pp. 